\title{
Global futures of trade impacting the challenge to decarbonize the international shipping sector
}

\author{
Eduardo Müller-Casseres a, *, Oreane Y. Edelenbosch ${ }^{\mathrm{b}}$, Alexandre Szklo a, \\ Roberto Schaeffer ${ }^{a}$, Detlef P. van Vuuren ${ }^{\text {b, c }}$ \\ a CENERGIA/PPE/COPPE, Universidade Federal Do Rio de Janeiro (UFRJ), Rio de Janeiro, Brazil \\ b PBL Netherlands Environmental Assessment Agency, The Hague, the Netherlands \\ ${ }^{\mathrm{c}}$ Faculty of Geosciences, Utrecht University, Utrecht, the Netherlands
}

\section{A R T I C L E I N F O}

\section{Article history:}

Received 14 December 2020

Received in revised form

8 July 2021

Accepted 19 July 2021

Available online 22 July 2021

\section{Keywords:}

International shipping

$\mathrm{CO}_{2}$ emissions

Integrated assessment modelling

IMO2050

\begin{abstract}
A B S T R A C T
International shipping accounts for around $2 \%$ of global $\mathrm{CO}_{2}$ emissions. The International Maritime Organization (IMO) has set the ambition to halve shipping GHG emissions by 2050 to help mitigate climate change. As shipping connects countries and sectors, its future development is highly dependent on regional and sectoral trends. So far, the literature on the decarbonization of shipping has focused on sectoral analyses while integrated assessment models (IAMs) have paid little attention to this matter. In this study, the IMAGE model is used to assess different futures of energy, agricultural and industry impacting the effort required to meet IMO's target for 2050. To that end, long-term seaborne trade projections are created from outputs of the IMAGE model. The results show that varying pathways of socio-economic development strongly affect the size of the sector. The mass shipped globally ranges from 17 to $35 \mathrm{Gt} / \mathrm{yr}$ in 2050. This corresponds to an energy demand between 9 and $25 \mathrm{EJ}$ in the same year, which would require significant amounts of low-carbon fuels. Interestingly, in a climate policy scenario, the avoided trade of fossil energy, although partially compensated by an increase of biofuel trade, lowers the international shipping mitigation effort.
\end{abstract}

() 2021 Elsevier Ltd. All rights reserved.

\section{Introduction}

The shipping sector is an important contributor to global greenhouse gas (GHG) emissions, accounting for approximately $1.06 \mathrm{GtCO}_{2} / \mathrm{yr}$ (direct emissions), most of which $\left(0.74 \mathrm{GtCO}_{2} / \mathrm{yr}\right)$ is associated with international ${ }^{1}$ freight transport [1,2] (this represents around $11 \%$ of total transport emissions [3]). Shipping activity is expected to further grow in the future, in light of historic trends

\footnotetext{
* Corresponding author. Energy Planning Program, COPPE, Universidade Federal do Rio de Janeiro, Centro de Tecnologia, Bloco C, Sala 211, Cidade Universitária, Ilha do Fundão, 21941-914, Rio de Janeiro, RJ, Brazil.

E-mail addresses: ecasseres@ppe.ufrj.br (E. Müller-Casseres), oreane. edelenbosch@pbl.nl (O.Y. Edelenbosch), szklo@ppe.ufrj.br (A. Szklo), roberto@ppe. ufrj.br (R. Schaeffer), detlef.vanvuuren@pbl.nl (D.P. van Vuuren).

1 The fraction of shipping emissions that falls into the category "international shipping" can be defined according to two different approaches, voyage- and vessel-based allocation. While the first defines international emissions as those which occur on a voyage between different countries, the latter defines international emissions according to ship types. The amount presented in the text derives from a voyage-based perspective [2].
}

(from roughly $0.6 \mathrm{Gt} / \mathrm{yr}$ in 1950 to $11 \mathrm{Gt} / \mathrm{yr}$ in 2018 [4,5]).

In 2018, the International Maritime Organization (IMO), the United Nations body responsible for environmental regulation of international shipping, established a preliminary strategy to reduce shipping-related GHG emissions. This strategy aims to achieve a pathway of GHG emissions consistent with the Paris Agreement temperature goals. This has been translated into the objective of limiting total emissions from international shipping in 2050 to $50 \%$ of the emission amount in 2008 [6]. While many mitigation scenarios aligned with the Paris Agreement often have similar reduction rates, other studies have recently questioned whether a $50 \%$ reduction is enough (among others because remaining emissions need to be compensated with negative emissions) [7-9]. Here, we focus on the IMO target. Considering this goal, hereinafter referred to as IMO2050, international shipping GHG emissions should be less than $0.40 \mathrm{GtCO}_{2} \mathrm{eq} / \mathrm{yr}$ in 2050.

Over the past decade, the IMO has adopted measures to reduce shipping GHG emissions. Among these measures, the Energy Efficiency Design Index (EEDI) policy is the most important example. Despite its name, the EEDI policy is a carbon intensity policy. It 
establishes $\mathrm{CO}_{2}$ emissions newbuilding standards $\left(\mathrm{gCO}_{2} / \mathrm{t}-\mathrm{nm}\right)$ for ships built after 2012, making it mandatory to increase the efficiency of new vessels [10]. Also, more recently, the IMO has introduced the Energy Efficiency Existing Ship Index (EEXI) [11]. On the operational side, the IMO has implemented the Ship Energy Efficiency Management Plan (SEEMP) policy. The SEEMP is an operational measure that seeks to help improve the energy efficiency of a ship in a cost-effective manner. It provides a practical approach for ship operators to monitor the fleet efficiency using the Energy Efficiency Operational Indicator (EEOI) [2]. In 2021, a rating scheme based on a mandatory Carbon Intensity Indicator (CII) was approved to strengthen SEEMP [12].

Besides, the establishment of IMO2050 has motivated several studies to analyze the opportunities to decarbonize the maritime sector more deeply. They show that there are many options to reduce the carbon intensity of shipping through new operational improvements, more efficient design and the use of alternative energy sources [13-18]. Also, some long-term sectoral scenarios have been developed. These show that under the assumption of no new policies, total 2050 emissions from international shipping could range between 1.0 and $1.8 \mathrm{GtCO}_{2} / \mathrm{yr}$. At the same time, mitigation scenarios relying mostly on low-carbon fuels indicate that it is possible to achieve the IMO target, with emissions around $0.6 \mathrm{GtCO}_{2} / \mathrm{yr}$ in 2040 and $0.4 \mathrm{GtCO}_{2} / \mathrm{yr}$ in 2050 [3,14,19]. A few scenarios from DNV GL indicate even the possibility of a full decarbonization of the sector by 2040, far beyond the IMO level of ambition [14].

The sectoral models used to develop these scenarios typically treat shipping demand as an exogenous variable. They, therefore, do not necessarily capture important connections to other aspects of the global economy. This is relevant as the shipping sector basically connects product flows across sectors and between regions and is therefore subject to regional and sectoral developments, impacted also by policy changes. Moreover, technological improvements and switching to alternative marine fuels will go hand in hand with similar developments occurring in other energy-using sectors. Therefore, to better understand the feasibility of the IMO2050 target, it is essential to analyze cross sectoral feedbacks and interactions to assess how the demand for shipping can evolve over time.

To that end, Integrated Assessment Models (IAMs) could be a useful tool. IAMs have extensively been used to explore the consequences of different long-term climate change mitigation strategies. They often contain a detailed representation of the world's energy, land use, agricultural and climate systems, as well as the different inter-linkages, cross-sector, cross-regions and over time [20-23]. Nevertheless, the long-term scenarios developed so far by IAMs pay relatively little attention to emissions from international transport - and often describe these emissions by means of a rather aggregated relationship with income. In most cases, IAMs use exogenous drivers to project the demand for shipping [19] and there is no differentiation of ship types, efficiency standards and motorization technologies. One exception to this is a recent work that used a national IAM to assess the impacts of achieving IMO2050 on the Brazilian energy and land use systems [24]. In the present study, which has global scope, by developing a shipping model within the integrated assessment model IMAGE [25], we use the IAMs unique opportunity to understand and project the demand for international shipping activity in the context of a wider description of the economy. We use this to explore the robustness of meeting the IMO2050 target under the uncertainty of global sectoral developments impacting the international shipping sector.

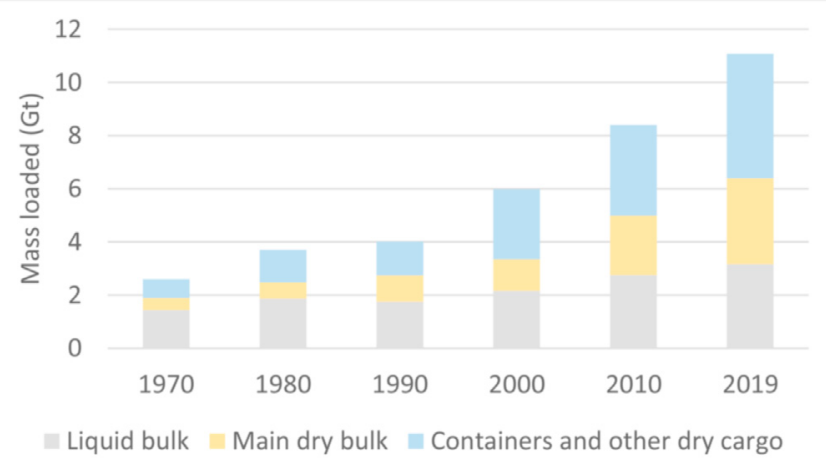

Fig. 1. Global seaborne trade activity between 1970 and 2019. Data: [5].

This article is organized in the following manner. After this introduction, an overview of the shipping sector is provided. Then, a brief description of the IMAGE model is presented. Subsequently, the methodology used to project trade and energy demand from an IAM perspective is detailed and the corresponding results are presented. Finally, concluding remarks and suggestions for future studies are explored.

\section{International shipping and IMO2050}

Fig. 1 shows the evolution of global seaborne trade between 1970 and 2019. The total mass loaded in merchant ships grew from $2.6 \mathrm{Gt} / \mathrm{yr}$ in 1970 to $11.1 \mathrm{Gt} / \mathrm{yr}$ in 2019 , with an average rate of increase equal to $34 \%$ per decade. Fifty years ago, maritime trade consisted mostly (55\%) of crude oil and petroleum products (in the figure referred to as liquid bulk). With the rise of the containershipping industry and the increase in trade of dry bulk commodities, the liquid bulk share gradually declined over this period. At present, approximately $29 \%$ of the mass loaded yearly on ships corresponds to oil and products, while another $29 \%$ refers to major bulk shipping (mainly coal, grains and iron ore). Other dry cargoes, including containers, account for the majority of seaborne trade (42\%) [5]. It is important to highlight the specificity of container shipping, which accounts for most of the growth of the sector over the last four decades. While liquid and dry bulk trade operate at lower speeds (12-15 knots), containerships have higher nominal speeds (20-25 knots), which implies a completely different consumption dynamic. The mitigation potential associated with slow steaming, for example, is much higher in the case of the container network [26,27].

Also in terms of average haul, seaborne trade has changed significantly over the past decades (Fig. 2). Until the mid-1970s, the typical distance traveled by merchant ships has grown robustly, exceeding 5000 miles around 1977, as a result of Middle East's increasing share in crude oil supply. Later, during the 1980s, the rise of new oil producing regions (e.g., North Sea and Mexico) caused a reduction in the seaborne average haul, which reached the level of 3700 nautical miles. Afterwards, the typical travelling distance started to rise again, led by products such as iron ore and petroleum products. In the 21st century, despite short-term fluctuations, the average haul remained approximately constant around 4900 miles. The current trend is still upwards, but intra-regional trading blocs are becoming more cemented [4,28].

As in other transport sectors, carbon dioxide $\left(\mathrm{CO}_{2}\right)$ emissions from shipping originate from the combustion of fossil fuels. 


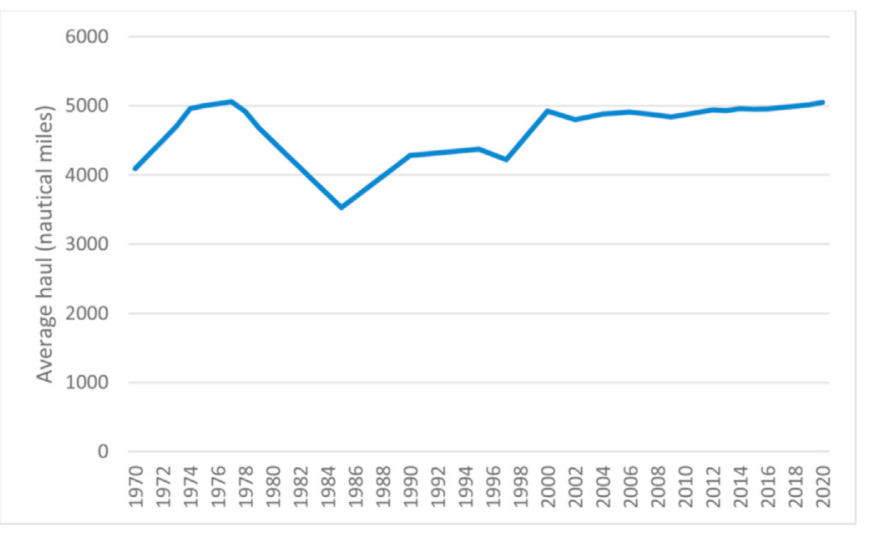

Fig. 2. Estimated average haul of world seaborne trade between 1970 and 2020. Data: $[5,28,29]$.

Specifically in the case of ships, they are burned to produce mechanical energy for propulsion, but also heat and electricity for use onboard the ship. Until the first half of the 20th century, coal was shipping's prevalent energy source but, since then it was completely replaced by oil products [30]. In 2018, heavy fuel oil (HFO) and marine gasoil (MGO), or more generally, bunker, ${ }^{2}$ accounted for $95 \%$ of the sector's energy demand [2]. The other $5 \%$ refers to liquefied natural gas (LNG), a newer marine fuel used mostly in a number of gas carriers. However, the entry into force of stricter air pollution regulations and the decrease in costs of using natural gas as a marine fuel are expected to increase LNG's participation also in other types of ship.

Fig. 3 shows total GHG emissions from shipping between 2012 and 2018, almost completely composed of $\mathrm{CO}_{2}$ emissions. ${ }^{3}$ In recent years, the proportion between international shipping $\mathrm{CO}_{2}$ emissions and total shipping $\mathrm{CO}_{2}$ emissions has been around $75 \%$. Fig. 2 also shows that there has been a relative stabilization of emissions over the 2010s, despite the increase in activity [2]. This is due to lower speeds practiced as a way to absorb idle capacity since the

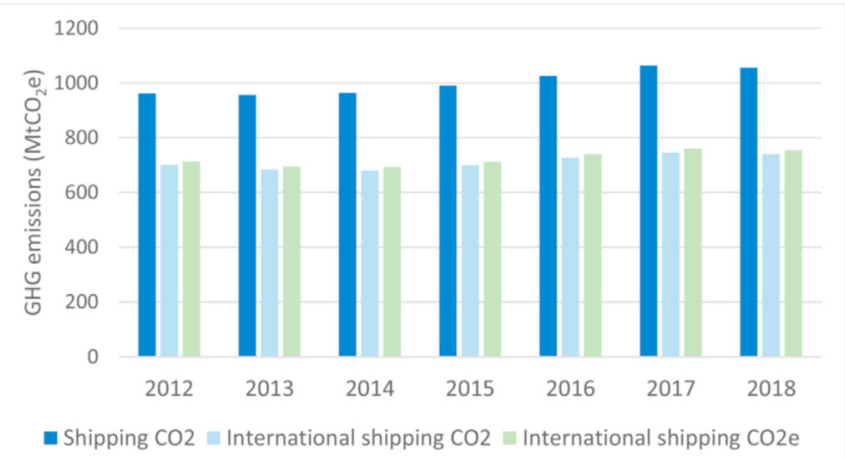

Fig. 3. Greenhouse gas emissions from international shipping between 2012 and 2018 considering a voyage-based allocation. Data: [2].

\footnotetext{
2 Actually, marine fuels are usually formed by a blend of HFO and MGO in varied proportions. Considering the similarity of these fuels regarding their energy conversion and carbon intensities, in this work, they are treated indistinctly under the designation "bunker".

${ }^{3}$ Methane and fluorinated gases make up the rest of greenhouse gas emissions from shipping.
}

2008 crisis [31,32], but also to relevant efficiency gains derived from the implementation of energy efficiency measures, such as the EEDI [10,33]. In 2020 specifically, there may have been an even more significant reduction in shipping emissions due to the global COVID-19 crisis [5]. However, in the long run, with the possible saturation of efficiency gains and the continued increase in international trade, emissions are expected to resume a growth trend $[2,3]$. Currently, international shipping emissions are approximately $300 \mathrm{MtCO}_{2} / \mathrm{yr}$ above the 2050 target. As discussed, this gap tends to become larger if activity increases. Therefore, it is likely that the decarbonization of shipping will require the use of significant amounts of low-carbon fuels.

\section{Methods}

In this section, the methods used to analyze the decarbonization of international shipping under the point of view of an IAM are explained. Fig. 4 provides an overview of the methodological procedure adopted in this work. In six different scenarios, bilateral mass-based trade matrices were created for 19 international shipping products from outputs of the IMAGE model, considering the timeframe 2000-2100. Then, the total energy demand associated with this seaborne trade was estimated using a simplified power model. Finally, for all six scenarios, the amount of low-carbon fuels required to meet IMO2050 was determined based on the total energy demand and the GHG emission limit set by IMO's target.

\subsection{The IMAGE model and the SSP narratives}

\subsubsection{The IMAGE model: utilization and structure}

The Integrated Model to Assess the Global Environment (IMAGE model) is a global IAM developed by the Netherlands Environmental Assessment Agency (PBL). It is a model framework that simulates the interactions between human societies, the biosphere, and the atmosphere to assess issues such as climate change, biodiversity and human well-being. Detailed technical information can be found on the IMAGE 3.0 Documentation webpage [34].

The IMAGE framework has been used extensively to assess global environmental challenges, most prominently climate change, land-use change, water scarcity and nutrient cycles. The complexity of these challenges, with often a global, long-term, cross-sectoral character call for a broad modelling scope. The IMAGE framework therefore includes a detailed representation of energy system dynamics, including energy producing sectors and their interactions with energy demanding sectors such as steel and cement production, freight and passenger transport, and residential and service sector buildings. The framework includes an economic model to project agricultural product demand and a detailed gridded assessment of land availability depending on land use and land cover. Compared to other IAMs, the framework has less detail on economics, but as a partial equilibrium simulation model a relatively comprehensive representation of sectors, regions and physical flows. This is of great importance for the proposed dynamic modelling of international shipping demand [25].

As discussed in section 2, energy, agricultural and industrial products form a large part of the products shipped by maritime

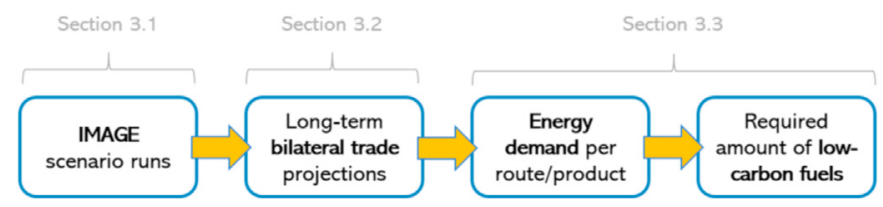

Fig. 4. Overview of the methodology. 
transport. In IMAGE, projected trade of energy and agricultural products depends on detailed resource supply and demand dynamics, including spatial resource availability, extraction costs, technology development, yield improvements, developing consumption patterns. The trade of materials, minerals, chemicals are not explicitly modelled in IMAGE, but their production and demand is. Here we briefly discuss the projected trade of the energy and agricultural products, and the projected production and demand of the remaining products, which form the starting point of international shipping demand projections [34].

3.1.1.1. Trade of energy products. In IMAGE, fossil fuel resource availability is modelled through long-term supply cost-curves that describe different resource categories associated with increasing cost levels. The cheapest deposits are assumed to be exploited first. Conversion losses in for example refining and liquefactions and technology development are projected to decrease over time but also respond to price signals. These developments combined with the resource depletion determine the final fossil fuel production costs. In the fuel trade model, each region can import fuel from other regions depending on the relative production costs and the transportation costs, which depends on the distance between regions. The distribution of imported fuel from supplying regions is based on a multinomial logit equation, where the cheapest supplying region has the largest share. To account for trade barriers due to political or geographical constraints an additional "cost" factor is added, determined by calibration. To simulate cartel behavior, regions that can supply at costs that are significantly lower than the production costs of the importing regions (the assumed threshold is $60 \%$ ), are assumed to supply at only slightly below production costs. The trade of biofuels has a similar structure as fossil fuel trade. However, there are a few important differences. First of all, the availability of biofuels depends on the land availability for commercial energy crops, with as important criteria that bioenergy crops can only be cultivated on either abandoned agricultural land or on natural grass land. Labor, land rent and capital costs are input in to the primary bioenergy production costs, and crop yield is calculated on the basis of the IMAGE crop model with $0.5 \times 0.5^{\circ}$ grid detail. The model distinguishes between two biofuel types, namely solid biofuels, used by the industry and power sector, and liquid biofuels which are mainly used by the transport sector.

3.1.1.2. Trade of agricultural products. The agricultural economy is simulated within the IMAGE framework by the MAGNET model [35], which is based on the standard GTAP model, with a multiregional, computable general equilibrium structure. Compared to GTAP, the model has a more detailed representation of land-use, household consumption, livestock, food, feed, energy crop production and emission reduction from deforestation components. The traded agricultural products are differentiated according to the country of origin, and as such not identical but imperfect substitutes following the Armington assumption [36]. The availability and suitability of land depends on information coming from the IMAGE land model, resulting in a dynamic land-supply function. The total land supply, similar to the case of biofuels, is calculated on a $5 \times 5$ arcminutes grid, and depends on the available land, and crop productivity related also to soil and climatic conditions and yields. The crop and pasture yields can change as a result of technological change, intensification, climate change, changes in agricultural area.

3.1.1.3. Production of industrial materials. The demand and production of cement, steel and chemicals are explicitly modelled in IMAGE. The demand for steel and cement are described as function of per capita economic activity, based on historic production and trade data between 1970 and 2012. A material production model then simulates how to fulfill this demand, based on trade, production stock turnover, material recycling and competing steel and cement production technologies. The calculated technology mix, depending also technology development and energy prices, determine the total energy demand originating from the steel and cement sector [37].

\subsubsection{The shared socioeconomic pathways (SSPS)}

The shared socioeconomic pathways (SSPs) are scenarios of global socio-economic development in the 21st century developed by the climate change research community to serve as a common reference in the long-term analysis of climate impacts, vulnerabilities, adaptation and mitigation ${ }^{4}$ [38-41]. This framework describes five internally consistent qualitative pathways of future changes in demographics, human development, economy, lifestyle, government and institutions, innovation and natural resources through consistent storylines. They have been frequently used as to assess the uncertainty in baseline development. The different pathways, varying in their perspective on economic growth, population growth, globalization, technology development (see table below) clearly also have an impact on projected trade of products. In this paper, these storylines are used to assess the uncertainty in demand for products traded through international shipping and how this impacts mitigation efforts. Table 1 concisely describes the narratives behind the five SSPs. In the supplementary material, Table 1 summarizes key aspects of the five SSPs [40-48].

\subsection{International trade}

As discussed in Section 2, the majority of international trade takes place by sea. In this subsection, we discuss the methodological procedure adopted to project the total international trade over the century (3.2.1) and to distinguish between seaborne and nonseaborne trade flows (3.2.2).

\subsubsection{Total international trade}

The analysis of international trade was done separately for 19 products or groups of products: 1) coal; 2) oil and oil products; 3 ) natural gas; 4) liquid biofuels; 5) solid biofuels; 6) chemicals; 7) iron ore; 8) steel products; 9) cement; 10) bauxite; 11) phosphate rock; 12) wheat; 13) maize; 14) rice; 15) soybeans; 16) vegetables and fruits; 17) other agricultural; 18) containers; 19) vehicles. For each one of these categories, mass-based trade matrices were created for the period 2000-2100 using relevant outputs from the IMAGE model and historical data. The dimension of these trade matrices $(27 \times 27)$ follows the geographical breakdown of the IMAGE model, which considers 26 actual world regions and one extra region. The assumptions adopted for each product/group of product are explained in Table 2 in the supplementary material.

\subsubsection{Seaborne trade}

Even though the seaborne mode is prevalent in international trade [49], road, rail, airlines and pipelines are also used to transport traded goods. As such, the results obtained using the methods explained in 3.2.1 include a few interregional flows that do not use maritime transportation, especially when it comes to adjacent regions. Some notable examples are the oil and/or gas flows such as Russia-China [50], Russia-Europe [51], Canada-USA [52], and Rest of

\footnotetext{
${ }^{4}$ IMAGE is one of the marker models that was used to formulate the SSP scenarios as one of the marker models. The same scenario formulation, which describes demographic, technology, lifestyle, economic changes that follow the different SSP narratives, is used in this study [42].
} 
Table 1

The shared socioeconomic pathways.

SSP Narrative

SSP1 The SSP1 narrative is characterized by a fast and sustainable development firmly based on global cooperation. This storyline includes high investments in health and education across countries and an increasing preference for green technologies [42].

SSP2 In the SSP2 narrative, a sort of midpoint between the other four SSPs, the efforts to foment global cooperation and achieve development and environmental goals are present but advance more slowly than in SSP1. Socioeconomic indicators progress compatibly with historic trends and there are no major technological disruptions [43].

SSP3 The SSP3 storyline is marked by an increasingly fragmented world. Competition, regional conflicts and security concerns make national governments focus on domestic issues. There is a narrower view of social development, highly dependent on local factors of production. Investments in health and education decline and inequality worsens [44].

SSP4 The worsening of socioeconomic disparities and the escalation of social stratification are the hallmark of this narrative. In the SSP4 world, the gap between increasingly rich, well-educated and globally connected humans and low-income, poorly educated people becomes wide open. Such disparities also grow between countries - an accelerated technological development observed in specific regions coexists with labor-intensive, low-tech economies across the globe [45].

SSP5 The SSP5 world is characterized by a high degree of social, technological and human development favored by international cooperation and a strong global market. Contrary to SSP1, the push for development is coupled with a preference for fossil fuels and the adoption of resource intensive lifestyles across the world. Investments in health, education and environmental management are high [46].

Table 2

Analyzed scenarios.

\begin{tabular}{|c|c|c|}
\hline \multicolumn{2}{|c|}{ Scenario Short description } & \multirow{2}{*}{$\begin{array}{l}\text { Climate policy } \\
\text { None }\end{array}$} \\
\hline SSP1 & $\begin{array}{l}\text { SSP1 baseline: low population, high economic and technology development (preference for green } \\
\text { technologies) }\end{array}$ & \\
\hline SSP2 & SSP2 baseline: medium assumptions & \\
\hline SSP3 & SSP3 baseline: high population, low economic and technology development & \\
\hline SSP4 & SSP4 baseline: medium population, unequal economic and technology development & \\
\hline SSP5 & $\begin{array}{l}\text { SSP5 baseline: low population, high economic and technology development (preference for fossil } \\
\text { technologies) }\end{array}$ & \\
\hline $\begin{array}{l}\text { SSP2- } \\
\text { mit }\end{array}$ & SSP2 mitigation scenario (standard) & $\begin{array}{l}\text { Climate policy compatible with a world well-below } \\
2^{\circ} \mathrm{C}\end{array}$ \\
\hline
\end{tabular}

South America-Brazil [53]. In some cases, e.g. between the different European regions (11-14), this is valid for all products. As such, prior to the calculation of the demand for maritime transport work, these trade flows were excluded from the original matrices.

\subsubsection{Selection of scenarios}

As discussed in item 3.1.1, the IMAGE framework includes several baseline and mitigation scenarios. In this work, considering the objective to capture the impact of the uncertainty of the global socioeconomic development on the international shipping sector, we worked with the five SSP baselines. Furthermore, in order to analyze the effects of a climate policy on the demand for shipping, a mitigation scenario was included in the study. Table 2 summarizes the characteristics of the six scenarios.

\subsection{Energy and emissions modelling}

To model the energy demand associated with trade, a simplified energy model was used. First, to determine the transport work per product and route, representative ports were assigned to the IMAGE regions and thereby distance matrices were created (item 3.3.1). Then, ship categories were assigned to the different routes and the roundtrip energy demand was calculated, considering main engines, auxiliary engines and boilers. Finally, the total energy demand was estimated based on the required number of roundtrips (item 3.3.2).

\subsubsection{Transport work}

The seaborne transport work (mass traded $x$ distance) was estimated based on the distances between representative ports, defined as ports of major regional importance. In the present context, they were considered to concentrate the imports and exports of a certain region. The travelling distances were calculated with the help of an online tool [54]. For most cases, the minimal distance between ports was used. However, chokepoints and typical ship sizes were also considered (for example, the Middle East-North Europe VLCC crude oil route goes around the Cape of Good Hope instead of going through the Suez Canal). The base distance matrix was defined considering representative oil terminals. For all other products, incremental changes were made in the base matrix to better represent trade specificities. Some of these changes are illustrated in Fig. 5. In the supplementary material, the representative ports are listed in Table 3.

\subsubsection{Energy demand}

For the energy modelling, different vessel types and sizes were considered. In the supplementary material, a table summarizing the ship classes used for each product is provided. In some cases, the vessel class considered for a certain product does not match exactly the actual existing ships. This is the case for general cargo ships, which are approximated as small bulk carriers. The roundtrip energy consumption is calculated using a simplified energy model that estimates the demand for mechanical energy (propulsion main engine), electricity (auxiliary engine) and heat (auxiliary boilers ${ }^{5}$ ). The propulsion energy demand is calculated through hydrodynamic equations $[17,55]$. The hull resistance $R_{T}$ and the associated brake power $P_{B}$ are presented in Eqs. (1) and (2), respectively.

$R_{T}=\frac{1}{2} \rho C_{T} S v^{2}$

$P_{B}=\frac{(1+m) R_{T} v}{\eta_{T}}$

\footnotetext{
5 The boiler is required in the case of viscous fuels, such as bunker, but not in the case of gaseous fuels and methanol.
} 


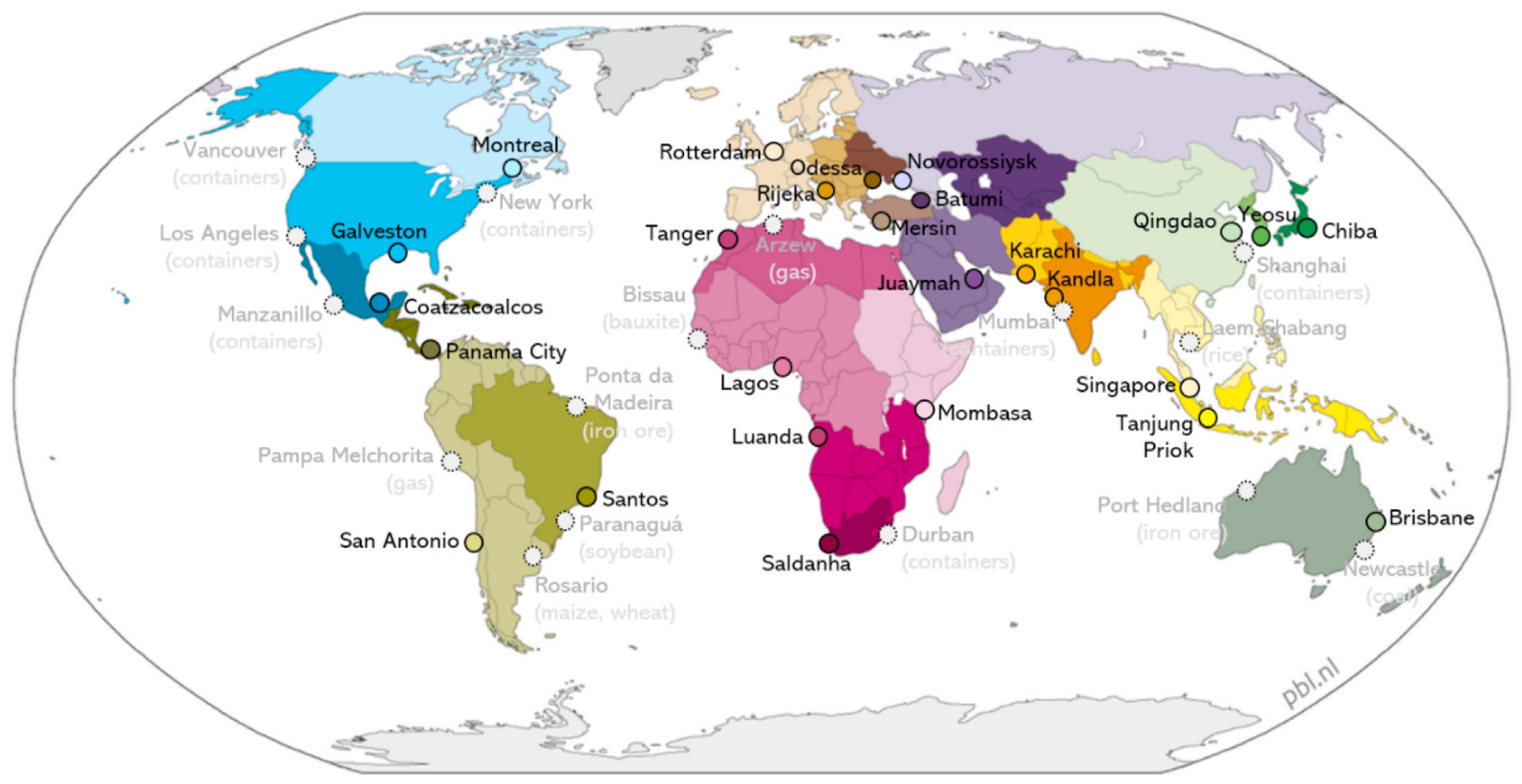

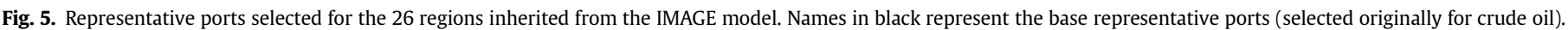
Names in grey are examples of changes in the base list to better represent other products.

Table 3

Efficiency scenarios.

\begin{tabular}{|c|c|c|c|}
\hline \multirow[t]{2}{*}{ Efficiency scenario } & \multirow[t]{2}{*}{ Description } & \multicolumn{2}{|c|}{ Efficiency gains relatively to 2000} \\
\hline & & 2050 & 2100 \\
\hline Incremental gains & More efficient hull design, energy efficiency policy & $30 \%$ & $35 \%$ \\
\hline High gains & Auxiliary propulsion devices, slow steaming & $40 \%$ & $50 \%$ \\
\hline
\end{tabular}

In Eqs. (1) and (2), $\rho$ is the seawater density, $C_{T}$ is the total resistance coefficient, $S$ is the wetted surface, $m$ is the sea margin, $v$ is the speed of the ship and $\eta_{T}$ is the total propulsion efficiency. These parameters are estimated based on ship sizes and categories. The estimation of auxiliary engines and boilers energy demand follows [56]. It considers typical loads for different operational modes (at-berth, at-anchorage, maneuvering and at-sea) [57-64]. The route's yearly final energy demand is determined by multiplying the roundtrip demand by the total number of trips, given by Eq. (3).

$n=\frac{M}{l f * d w c c}$

In Eq. (3), $n$ is the number of trips, $M$ is the total mass traded, If is the load factor and $d w c c$ is the deadweight cargo capacity. For the energy calculation, laden and ballast voyage load factors were distinguished (ballast deadweight was taken to be $30 \%$ of the total deadweight as an approximation). For the conversion from final to fuel energy demand, an average specific fuel consumption (SFC) of $7.3 \mathrm{MJ} / \mathrm{kWh}$ is adopted $[56,65,66]$. This SFC, equivalent to an efficiency of $49 \%$, is consistent with the conversion of almost all fossil

\footnotetext{
${ }^{6}$ In terms of energy, the conversion efficiency is approximately the same for the different fuels in the case of internal combustion engines. For HFO and MGO, for example, it is around 7.2 MJ/kWh. For LNG and SVO, it is around 7.3 MJ/kWh. For methanol and FT-bunker, it is around $7.5 \mathrm{MJ} / \mathrm{kWh}$. However, the efficiency can be significantly higher in the case of an electrochemical conversion. For ammonia in a fuel cell system, for instance, it is around $6.0 \mathrm{MJ} / \mathrm{kWh}$ (or $60 \%$ ).
}

and renewable marine fuels. ${ }^{6}$ The results are calibrated according to the data on fuel consumption from the Fourth IMO GHG Study [2], using the period 2012-2018 as a reference. To model efficiency gains, two scenarios are considered, one more conservative and another assuming higher gains. These high gains do not necessarily come from efficiency stricto sensu, but eventually from other highimpact mitigation measures such as the deployment of auxiliary propulsion devices and slow steaming. Table 3 describes the two efficiency scenarios.

\section{Results}

\subsection{International trade scenarios}

Fig. 6 shows the evolution of global seaborne trade in the six scenarios. In all scenarios, there is an increase in the total exchange of goods between countries over the century. However, how fast global trade increases depends on the SSP. In SSP2, for example, global trade grows from around $11 \mathrm{Gt} / \mathrm{yr}$ in 2020 to $22 \mathrm{Gt} / \mathrm{yr}$ in 2050 and $33 \mathrm{Gt} / \mathrm{yr}$ in 2100. In SSP5, with a highly connected and competitive global market, the rise is much larger, reaching $35 \mathrm{Gt} /$ year in 2050 and $53 \mathrm{Gt} / \mathrm{yr}$ in 2100. In the case of SSP1, until midcentury, the trajectory is similar to the one observed in SSP2. From that point on, the increasingly strong preference for local resources and technologies causes a stabilization of trade around $20 \mathrm{Gt} / \mathrm{yr}$. The slow development and regional isolation observed in SSP3 entail a relatively low global trade, especially until 2050 $(18 \mathrm{Gt} / \mathrm{yr})$. Nevertheless, in the second half of the century, with very 


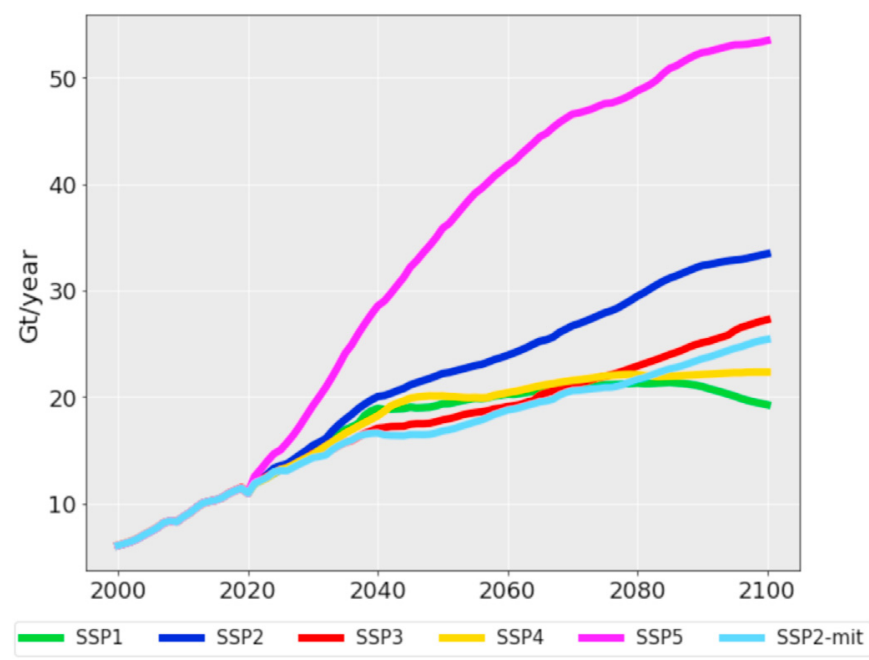

Fig. 6. Global seaborne trade in the six scenarios.

high world population and low technological efficiency, the increase in trade goes on, reaching $27 \mathrm{Gt} / \mathrm{yr}$. The development of global trade in SSP4 is somehow an intermediate stage between SSP1 and SSP3. In the SSP2 mitigation scenario, international trade follows a trend similar to that of its baseline. However, over the three decades between 2020 and 2050, a gap is created between these two scenarios. This is mainly due to an avoided trade of fossil fuels in SSP2-mitigation.

Table 4 shows the average cargo travelling distance in the six scenarios in 2050. The average haul varies between slightly below 5000 (SSP2-mit scenario) and slightly above 5300 (SSP5 scenario) nautical miles, illustrating different trade network patterns according to the SSPs. While in SSP5 there is a strong signal towards a single global market, in SSP3, regional exchanges dominate. In the case of SSP2-mit, the low average haul is explained by the avoided trade of oil, a product that typically involves long-distance shipping.

Figs. 7 and 8 show the results breakdown by group of product and world regions. The variation in projected trade across the scenarios is significant for all products, but most pronounced for the trade of energy products. The results for specific products are discussed in items 4.1.1 to 4.1.8.

\subsubsection{Coal}

In most SSPs, given the low cost of coal-based electricity, in the absence of a climate policy, the use of coal continues to increase, especially in India and China. As such, in almost all baseline scenarios, the trade of coal grows significantly between 2020 and 2040 , peaking around 2045 . The height of this peak varies widely across the SSPs. In SSP2, it is equal to $5.7 \mathrm{Gt} / \mathrm{yr}$, with a stabilization at approximately $4.0 \mathrm{Gt} / \mathrm{yr}$ (twice as much as 2020) in the second half of the century. In SSP5, a world that indiscriminately uses fossil resources, this peak equates $10.5 \mathrm{Gt} / \mathrm{yr}$. Furthermore, after a slight

Table 4

Average haul in the six scenarios.

\begin{tabular}{ll}
\hline Scenario & Average haul in $2050(\mathrm{~nm})$ \\
\hline SSP1 & 5040 \\
SSP2 & 5289 \\
SSP3 & 4981 \\
SSP4 & 5243 \\
SSP5 & 5305 \\
SSP2-mit & 4964 \\
\hline
\end{tabular}

decline between 2050 and 2060, the fossil-based economic development of regions like Western and Eastern Africa causes a new rise in the trade of coal (equal to $12.3 \mathrm{Gt} / \mathrm{yr}$ in 2100). Contrastingly, in SSP1, the peak takes place way sooner and at a much lower level (4.2 Gt/yr in 2040). Then, it declines consistently over the century, reaching $1.8 \mathrm{Gt} /$ year in 2100. In SSP3, no peak is observed and the trade of coal increases significantly after 2050, reaching $6.5 \mathrm{Gt} / \mathrm{yr}$ in 2100 . In the mitigation scenario, electricity supply shifts gradually towards renewable-based facilities. As a result, the trade of coal declines over the century, reaching $1.0 \mathrm{Gt} / \mathrm{yr}$ in 2050 and $0.5 \mathrm{Gt} / \mathrm{yr}$ in 2100 .

\subsubsection{Oil and products}

The trade of petroleum and products, mostly driven by the demand of the transport sector, vary broadly across the six scenarios. In the SSP2 baseline, even though the amount imported by OECD countries declines, the total trade of oil increases steadily until 2080, reaching $4.5 \mathrm{Gt} / \mathrm{yr}$. This is mainly due to the imports of regions like Africa, India, Indonesia and South America, where the electrification of the transport sector happens slowly, in contrast with OECD countries. In SSP1, the trend of electrification is stronger all over the world. As such, the use of petroleum products is moderate even in these regions, enabling a significant reduction of the global oil trade (2.6 Gt/yr in 2050, $2.0 \mathrm{Gt} / \mathrm{yr}$ in 2100). In SSP5, the fossil-powered development of the whole world relies heavily on the global petroleum market. Thus, a steep increase is observed in the trade of oil over the century, reaching 7.0 Gt/yr around 2075. However, after that, the continuing electrification of the transport sector slightly reduces the oil trade. In SSP3, in spite of slow development and low international cooperation levels, the energy demand is high, and there is a preference for fossil resources. Therefore, even though the global oil market is weakened, accounting for a smaller fraction of the oil consumption, in absolute terms, the trajectory followed by the oil trade is similar to SSP2, but reaching a highest point in the last decades of the century $(5.9 \mathrm{Gt} / \mathrm{yr}$ in 2100). In the presence of a climate policy, the electrification of the passenger transport progresses at a stronger pace. Furthermore, biofuels are increasingly used in freight road transport and aviation. This brings about a consistent decline of oil trade, reaching $2.2 \mathrm{Gt} / \mathrm{yr}$ in 2050 and $1.2 \mathrm{Gt} / \mathrm{yr}$ in 2100.

\subsubsection{Natural gas}

The global natural gas market follows very different trends in the six studied scenarios. In SSP2, for instance, as the cleanest fossil fuel, natural gas assumes a prominent role, compatible with a middle of the road narrative. As such, the trade of gas increases robustly over the 21st century, growing from $0.6 \mathrm{Gt} / \mathrm{yr}$ in 2020 to $1.6 \mathrm{Gt} / \mathrm{yr}$ in 2050 and $3.3 \mathrm{Gt} / \mathrm{yr}$ in 2100 . Most of the gas is imported by Asian countries, but also by Africa and Europe. In SSP5, a very similar trend is observed. Contrary to what is perceived for the other fossil fuels, the gap between SSP2 and SSP5 is not wide. With the fossil-fueled development prioritizing coal and oil, these energy sources supply a high fraction of the world's energy demand, leaving less room for gas. In the SSP1 baseline, the trade of natural gas is especially important in the first half of the century $(1.7 \mathrm{Gt} / \mathrm{yr}$ by 2050), serving as a transition fuel. In the long term, the fuel gradually loses ground to greener technologies (e.g., wind, solar and biomass in power systems). In the end of the century, gas trade equals $1.5 \mathrm{Gt} / \mathrm{yr}$. A different trend is observed for the SSP3 baseline. In a world where global markets are weakened, the trade of natural gas, whose transportation is more costly than coal and oil, is severely affected. Global gas exchanges decrease from $0.6 \mathrm{Gt} / \mathrm{yr}$ in 2020 to $0.4 \mathrm{Gt} / \mathrm{yr}$ in 2060 . In the second half of the century, the trade of gas increases, reaching $1.3 \mathrm{Gt} / \mathrm{yr}$ in 2100 . In the mitigation scenario, the role of natural gas is similar to the one described for 

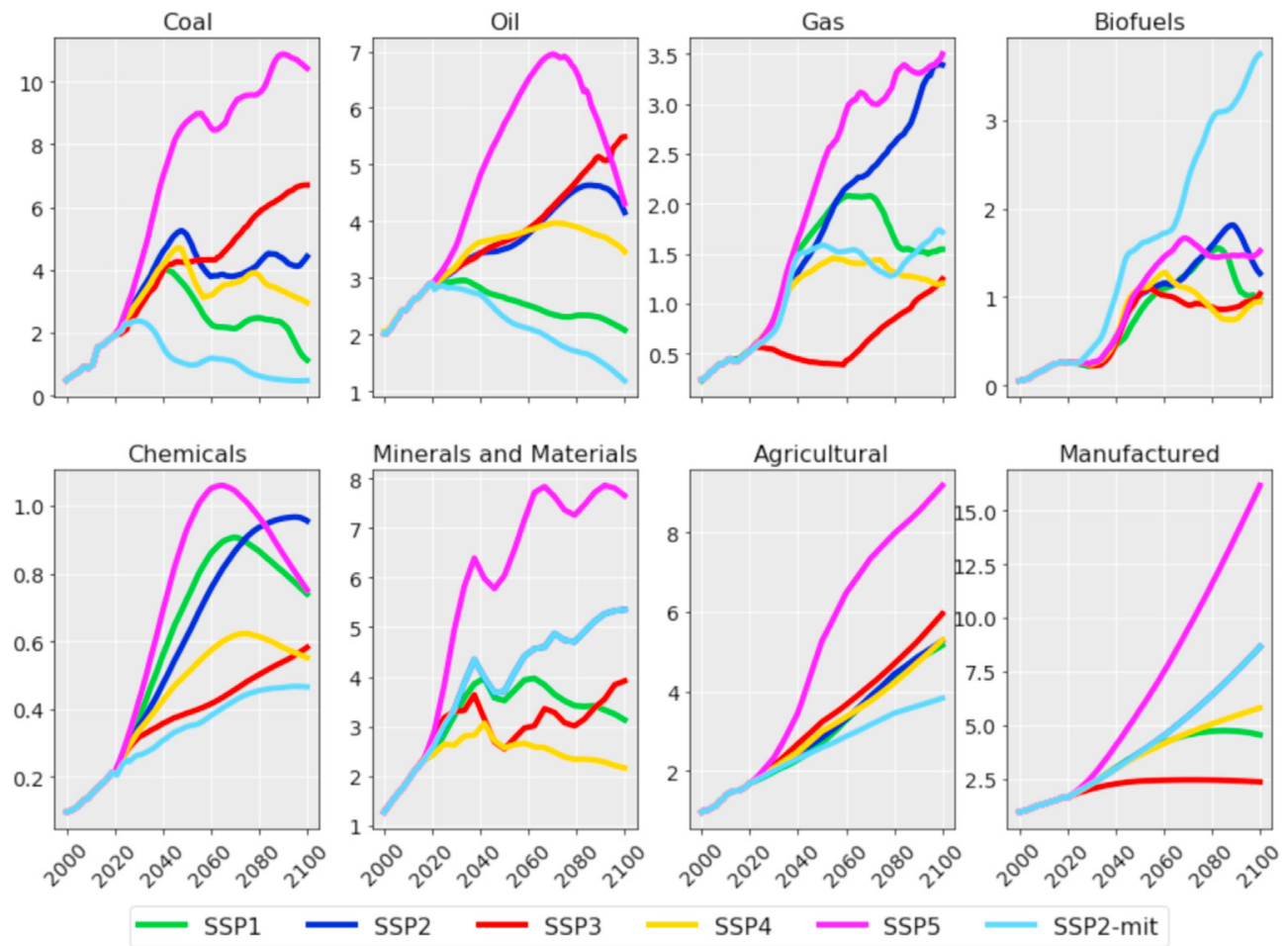

Fig. 7. Global seaborne trade in the six scenarios breakdown by group of products. Unit: Gt/yr.
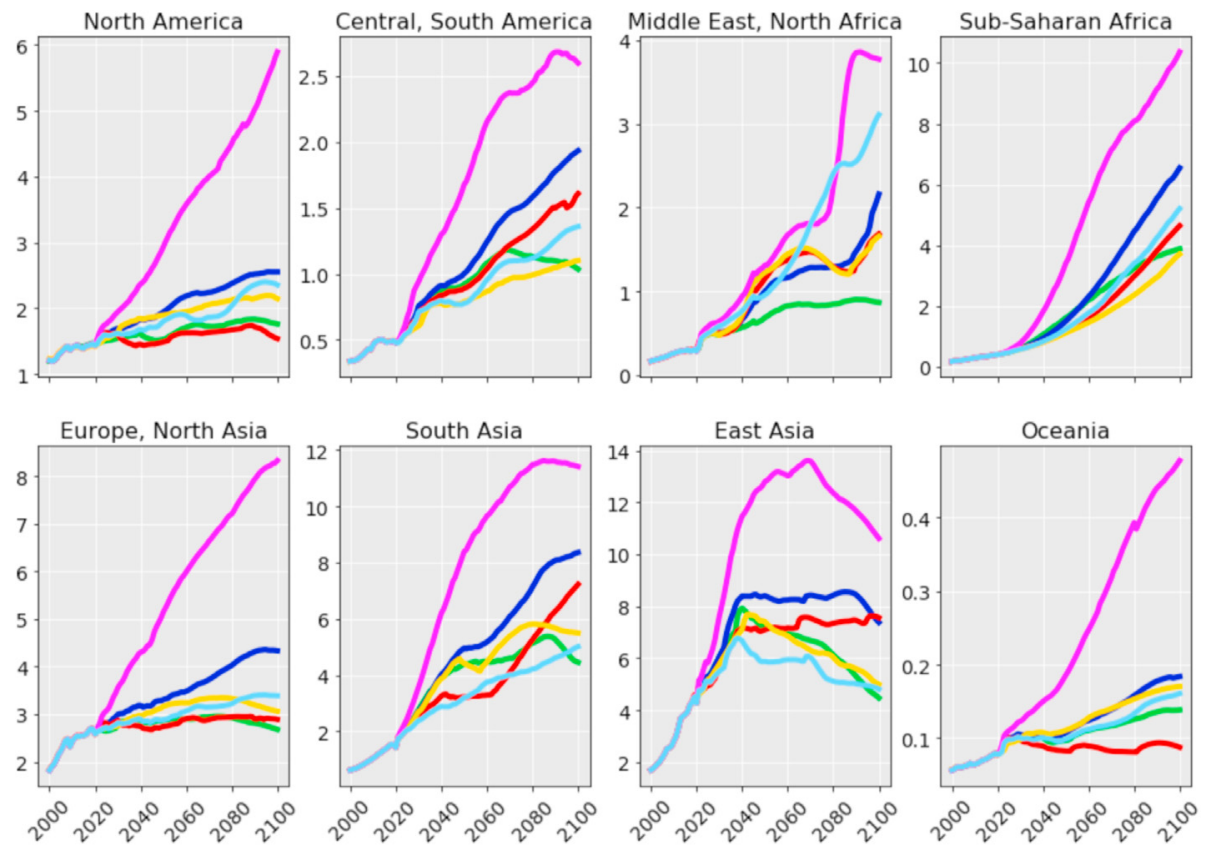

- SSP1

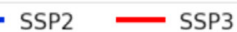

SSP4 SSP5

SSP2-mit

Fig. 8. Global seaborne trade in the six scenarios breakdown by importing region. Unit: Gt/yr.

SSP1. Thanks to its lower emission factor, gas is used a transition fuel for heat and electricity generation. However, carbon-free technologies are stronger in this scenario than in SSP1 and, therefore, less gas is used and traded.

\subsubsection{Biofuels}

The biofuel trade follows similar pathways in all baseline scenarios, especially until 2050 , when it reaches approximately $1.0 \mathrm{Gt} / \mathrm{yr}$. In SSP1, SSP2 and SSP5 the increasing yields push the trade further, showing that there is still room for the market to grow. In the climate mitigation scenario, the demand for lowcarbon fuels ramps up the trade of biofuels quickly, reaching $1.6 \mathrm{Gt} / \mathrm{yr}$ in 2050 , and $3.9 \mathrm{Gt} / \mathrm{yr}$ in 2100 . This is largely driven from the demand for BECCS to provide Carbon Dioxide Removal (CDR). 


\subsubsection{Chemicals}

In the first half of the century international trade of chemicals grows rapidly as many regions increase the demand of plastics and fertilizers. As most scenarios show a declining global population after mid-century, combined with structural changes requiring fewer chemicals (i.e., reduced fertilizer demand in SSP1), there is a large drop in the trade of chemicals post 2050. In the mitigation scenario, changes in consumer behaviour and the increased cost of petrochemicals reduce this demand and trade.

\subsubsection{Minerals and materials}

The trade of minerals and materials varies substantially across the scenarios. Both SSP2 and SSP2-mitigation project an increase in the trade of these products, especially iron ore. In these scenarios, the trade grows from around $2.5 \mathrm{Gt} / \mathrm{yr}$ in 2020 to $4.0 \mathrm{Gt} / \mathrm{yr}$ in 2050 and $5.2 \mathrm{Gt} / \mathrm{yr}$ in 2100 . On the other hand, the SSP1 baseline, which is characterized by a less material-intensive industry, has a lower trade, especially in the second half of the century. The lower limit corresponds to SSP4 - in a world where inequalities persist and worsen, poor countries dot not develop their infrastructure and industry and this severely impacts the trade of steel and iron ore.

\subsubsection{Agricultural products}

Total agricultural trade follows similar trends in most of the scenarios analyzed, with an increase from $1.8 \mathrm{Gt} / \mathrm{yr}$ in 2020 to around $2.5 \mathrm{Gt} / \mathrm{yr}$ in 2050 and $5 \mathrm{Gt} / \mathrm{yr}$ in 2100 . However, the drivers of this trade differ across scenarios. SSP1 and SSP3, for example, follow a very similar trajectory. However, while for the latter the increase in trade is mostly associated with a huge growth of the global population, in the case of SSP1, whose world population is much lower, this increase is related to the abolishment of tariffs and exports subsidies (i.e., the ratio between agricultural trade and agricultural production is much higher). In SSP5, with high demands from the food system (caused, for instance, by the rise of meat-rich diets), the trade of agricultural products grows faster, reaching $5 \mathrm{Gt} / \mathrm{yr}$ in 2050 and $9 \mathrm{Gt} / \mathrm{yr}$ in 2100. Contrastingly, the mitigation scenario is marked by a lower agricultural trade, especially after 2050 (4 Gt/yr in 2100).

\subsubsection{Manufactured goods}

In view of the higher consumption of goods and services, in addition to a crescent population, the trade of manufactured products surpasses today's level $(1.9 \mathrm{Gt} / \mathrm{year})$ in all scenarios. In SSP2, for example, it reaches $3.0 \mathrm{Gt} /$ year in 2050 and $6.2 \mathrm{Gt} / \mathrm{year}$ in 2100. In SSP5, with a much higher private consumption due, for example, to the dissemination of materialism and status consumption, the trade of manufactured goods is extremely high $(7 \mathrm{Gt} /$ yr in 2050, $16 \mathrm{Gt} / \mathrm{yr}$ in 2100). The exception is SSP3, in which a fragmented world and slow economic development contribute to weaken the global trade. In this scenario, trade stabilizes around $2.5 \mathrm{Gt} / \mathrm{yr}$ from 2030.

\subsection{Energy demand and required amount of renewable fuels}

Fig. 9 shows, for the six scenarios, the $\mathrm{CO}_{2}$ emissions associated with international shipping in the case of a completely fossil-fueled fleet. On the right side of the figure, the BAU/no ambition emission estimates for 2050 from DNV GL and IMO are also shown [2,14]. The presented emissions ranges are estimated based on the two vessel efficiency storylines while the percentage indicates the proportion of total global $\mathrm{CO}_{2}$ emissions coming from international shipping. For most scenarios, international shipping emissions lie between 1.0 and $1.7 \mathrm{GtCO}_{2} / \mathrm{yr}$ in 2050 (in line with IMO and DNV GL). The exception is SSP5, in which emissions reach the level of 2.0-2.5 $\mathrm{GtCO}_{2} / \mathrm{yr}$ in 2050 when considering $100 \%$ fossil-based energy. For baseline scenarios, the $\mathrm{CO}_{2}$ emission share of the sector lies between 2 and $4 \%$ in 2050. For the mitigation scenario, the proportion of shipping is way higher ( $13 \%$ ), since global $\mathrm{CO}_{2}$ emissions are at a much lower level due to mitigation in other sectors. In 2100, the proportion is negative ( $-18 \%$ ) because, with large-scale deployment of carbon dioxide removal (CDR), global net $\mathrm{CO}_{2}$ emissions go negative.

Fig. 10 shows, for both efficiency storylines, the amount of lowcarbon fuels required to meet the IMO2050 target per scenario. In both cases, taking the absolute goal for 2050 into account, the fossil energy is limited to approximately $6 \mathrm{EJ} / \mathrm{yr}$. As such, considering incremental gains, the total energy demand from international shipping varies from 12 to $25 \mathrm{EJ} / \mathrm{yr}$, implying a demand for renewable fuels between 6 and $17 \mathrm{EJ} / \mathrm{yr}$ in 2050. With high efficiency, the range for total energy is $9-17 \mathrm{EJ} / \mathrm{yr}$, with a demand for renewable energy between 3 and $11 \mathrm{EJ} / \mathrm{yr}$. For the sake of comparison, the world yearly biofuel production in 2018 was around 3 EJ [67].

To that end, several low-carbon fuels could be used. Concerning biofuels, the options can be divided in three groups [24]. The first group is composed of first-generation distilled biofuels, for instance straight vegetable oils (SVO), hydrotreated vegetable oils (HVO), and biodiesel, usually produced from animal fats and oilseeds [68]. The second group comprises advanced biofuels obtained through thermochemical processes, e.g. bio-oils, such as hydrotreated pyrolysis oils (HDPOs) [69] and Fischer-Tropsch (FT) synthetic liquids [70]. Advanced biofuels conversion facilities frequently output various hydrocarbon cuts, similarly to oil refineries. For example, biojet and FT-naphtha have higher market value than the

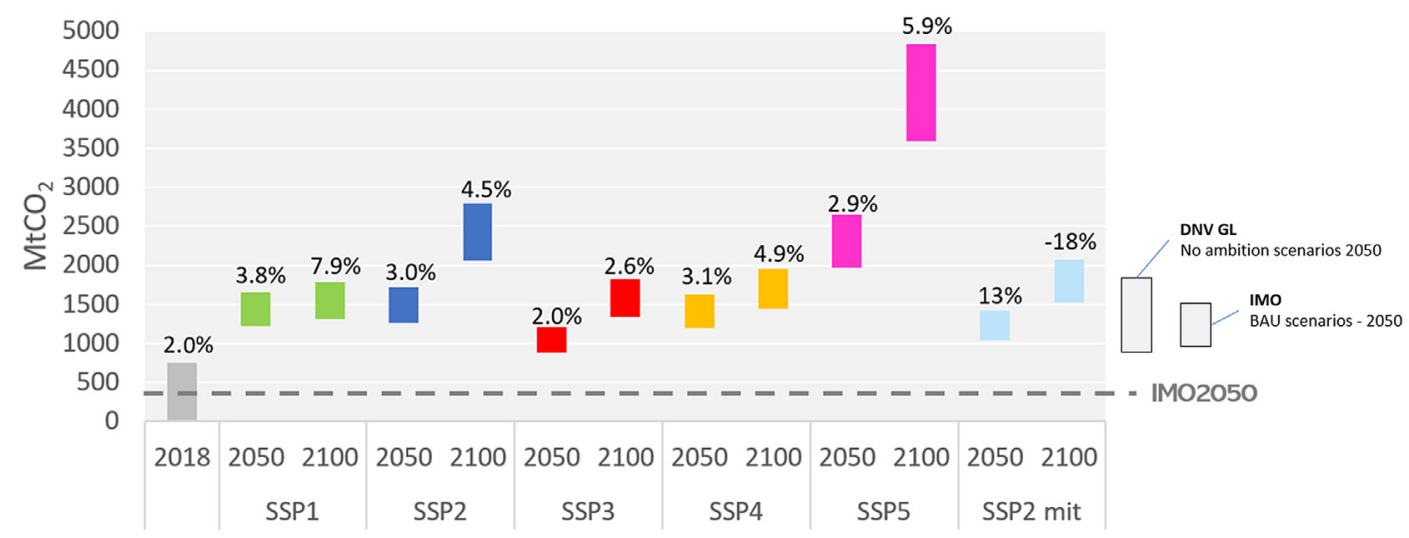

Fig. 9. $\mathrm{CO}_{2}$ emissions with a fossil-fueled fleet. The percentage above each bar indicates the ratio between international shipping and total $\mathrm{CO}_{2}$ emissions. 


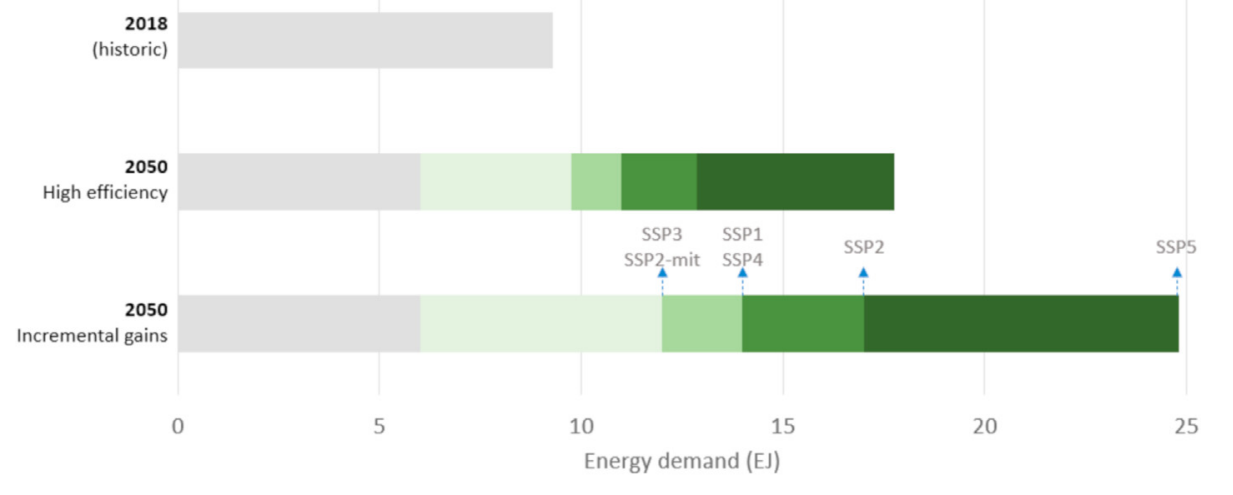

Fig. 10. Required renewable energy demand to meet the IMO2050 target.

coproduced fractions suited for marine use. As such, advanced biofuels for shipping can be regarded as byproducts, which could be a major advantage in terms of cost. The third group corresponds to biogases and bio-alcohols suited to the increasingly common dualfuel marine engines. Examples are liquefied biomethane (bio-LNG) and biomethanol. Low-carbon energy carriers for shipping can also be produced from hydrogen ( $\mathrm{H}_{2}$-fuels) [24]. This includes not only hydrogen for direct use but additionally ammonia $\left(\mathrm{NH}_{3}\right)$ and synthetic fuels. Although $\mathrm{H}_{2}$-fuels do not imply direct fossil GHG emissions, they can be fossil-based. Therefore, for $\mathrm{H}_{2}$-fuels to be considered low-carbon, they must be either renewable-based (green $\mathrm{H}_{2}$-fuels) or fossil-based with CCS (blue $\mathrm{H}_{2}$-fuels). In any case, all low-carbon fuels face technical-economic obstacles (e.g., competition for land, water stress, production technology readiness, applicability to the existing fleet, safety concerns, energy density, deployment of CCS) and scaling up their production and use to the required levels of 3-17 EJ might be a challenge.

\section{Discussion and conclusions}

The aim of this work was twofold. The first objective was to develop a methodological framework for the coupling of an IAM with a detailed model of international shipping in order to capture the impacts of different integrated scenarios on the demand for seaborne trade over the 21st century. The second objective was to use this integration to project the energy demand from shipping in the six scenarios studied, ultimately to better understand how different global trade futures impact the effort required, in terms also of the amount of renewable fuels needed, to meet the IMO2050 target.

The development of the shipping model followed a demanddriven approach based on socioeconomic and technological outputs of the IMAGE model. Starting from these variables, and considering the 26 IMAGE regions, yearly mass-based trade matrices were generated for each product. Thereby, it was possible to obtain long-term projections of global trade according to six scenarios, namely the five SSP baselines and one climate policy scenario.

International seaborne trade follows very different trends in the six scenarios studied (17-35 Gt/yr in 2050 and 19-53 Gt/yr in 2100 compared to $11 \mathrm{Gt} / \mathrm{yr}$ in 2020). The results are a function of the preference for certain energy carriers and of economic development in general, but they also depend heavily on consumption patterns and global cooperation levels. For instance, one could expect, given the low techno-economic efficiency and high population observed in SSP3, that this scenario would imply a high demand for shipping. Instead, during most of the century, SSP3 represents the lower end of the baseline trade projections in this study. This is due to a weakening of global cooperation, which causes each region to focus on its own mineral, agricultural and energy resources, following a logic of regional rivalry. Contrastingly, for all products, the upper end of global trade is defined by the SSP5 baseline, whose storyline includes fast development, high consumption, and a strong globalization. In this sense, SSP5 behaves as an outlier compared to the rest of scenarios. The remaining baselines lie somehow in-between, always closer to the lower end. In the middle of the road baseline, global trade doubles in 2050 and triples in 2100.

As countries' economies mature and develop into more service-oriented ones, the seaborne trade-intensity of imports and exports are likely to change into the future, which may have implications in the context of the different global scenarios we explore in this study. However, over the 2050 time horizon of our analysis, China is very likely to remain the main producer of energy converters associated low-carbon energy futures (solar PVs, electric batteries, electric vehicles etc.), and as such it will very likely remain the main processor of ores (and as such the main importer of mineral commodities), even as it moves to a more serviceoriented economy. Consequently, up to 2050 the Chinese economy will continue to dominate global seaborne trade (resource intensive imports and manufactured intense exports), which does not challenge the robustness of our results. However, future studies must further investigate the impact of industrialization on the profile and main routes of seaborne trade into the future.

Climate policy results in a lower demand for international shipping due to reduced fossil energy trade. In the presence of a climate policy compatible with a world well-below $2{ }^{\circ} \mathrm{C}$ (SSP2mitigation), an avoided demand of coal, oil, gas and chemicals reduces the international maritime activity by around $20 \%$ in 2050 and $25 \%$ in 2100 . The drastic increase in the trade of biofuels does not compensate the reduction seen in the other energy sectors. As such, it can be said that the results indicate an interesting positive feedback effect of the energy supply transition on the shipping sector. At the same time, the shipping model used in this study does not capture potential activity growths due to increased trade of products associated with the renewable energy supply chain, such as materials for batteries, solar panels, electric motors and even hydrogen. It is also worth noting that the IMAGE model is not able to see important details of the petroleum industry, such as different crude oil streams and refinery schemes. In this sense, our results for the mitigation scenario might underestimate a technological inflexibility that could keep the trade of oil and products at a fixed bottom level.

In a more conservative efficiency scenario, the total energy 
demand from international shipping lies in the range 12-25 EJ in 2050 and 18-46 EJ in 2100. With higher efficiency gains, the demand lies in the range 9-17 EJ in 2050 and 13-32 EJ in 2100. The conservative scenario reflects a business-as-usual storyline for efficiency improvements, with incremental gains. The high efficiency scenario reflects a more disruptive development of the mitigation measures, for example with the use of auxiliary propulsion devices and the existence of speed limits.

With a fossil-fueled fleet, international shipping emissions lie between 0.8 and $2.6 \mathrm{GtCO}_{2} / \mathrm{yr}$ in 2050 , with most scenarios (SSP1, SSP2, SSP2-mit and SSP4) in agreement with the literature. Existing scenarios that depict a fossil-fueled fleet project international shipping emissions between 1.0 and $1.8 \mathrm{GtCO}_{2} / \mathrm{yr}$ in 2050. This means that the central projections well align with the literature but that some scenarios go beyond the literature range, i.e., the low economic growth (SSP3) scenarios with high vessel efficiency (0.8 GtCO2/yr), and high growth SSP5 scenarios (2.0-2.6 $\mathrm{GtCO} / \mathrm{yr}$ ). Given the focus of these storylines, the broader emissions range is a coherent result.

Renewable fuels need to make up the bulk of shipping's energy supply in 2050 (3-17 EJ) if the IM02050 target is to be met. With fossils restricted to ca. $6 \mathrm{EJ}$ in all scenarios, the fulfillment of IMO2050 would require a steep increase in the global renewable fuel production. To that end, several low-carbon fuels can be considered. They can be more or less interesting depending on factors such as their applicability, cost and sustainability but, in any case, the scaling-up of their production to the levels indicated by our calculation represents a major challenge.

It is worth noting that this work was based on an ex-post analysis. The trade projections developed are based on scenario outputs of the IMAGE model. As such, the modelling is to a certain extent static and does not take into account year-by-year feedbacks. In future works, the authors intend to fully integrate the shipping module used here into the IMAGE model. Thereby, it will be possible to represent specific alternative marine fuels that will be part of the overall optimization. Furthermore, it must be stressed that although IMAGE contains relatively high sectoral and regional detail, as a partial equilibrium simulation model it represents less macro-economic detail. Input-output tables and also the global trade analysis project (GTAP) contain detailed trade flows and computable general equilibrium (CGE) consistent economic feedbacks but less suitable to represent the future changes and storylines as we have examined in this paper.

\section{Credit author statement}

Eduardo Müller-Casseres: conceptualization, methodology, investigation, writing - original draft, writing - review \& editing. Oreane Y. Edelenbosch: conceptualization, methodology, investigation, writing - original draft, writing - review \& editing. Alexandre Szklo: conceptualization, methodology, writing - review \& editing. Roberto Schaeffer: conceptualization, methodology, writing - review \& editing. Detlef P. van Vuuren: conceptualization, methodology, writing - review \& editing.

\section{Declaration of competing interest}

The authors declare that they have no known competing financial interests or personal relationships that could have appeared to influence the work reported in this paper.

\section{Acknowledgements}

The research carried out for this paper was supported by the Brazilian National Council for Scientific and Technological
Development (CNPq). This work also received funding from the NAVIGATE project of the European Union's Horizon 2020 research and innovation program under grant agreement no 821124 . Furthermore, this project has received funding from the European Union's DG CLIMA and EuropeAid under grant agreement no. 21020701/2017/770447/SER/CLIMA.C.1 EuropeAid/138417/DH/SER/ MulitOC (COMMIT). The authors would also like to thank HarmenSytze de Boer, Jonathan Doelman, Vassilis Daioglou and Willem-Jan van Zeist for their helpful comments. The authors are also grateful to the two anonymous reviewers for their careful reading and suggestions.

\section{Appendix A. Supplementary data}

Supplementary data to this article can be found online at https://doi.org/10.1016/j.energy.2021.121547.

\section{References}

[1] Olmer N, Comer B, Roy B, Mao X, Rutherford D. Greenhouse gas emissions from global shipping, 2013-2015. Washington DC. 2017.

[2] IMO. Fourth IMO GHG study 2020. 2020. https://doi.org/10.1017/ CBO9781107415324.004.

[3] IEA. International shipping: tracking report. 2020 [Online]. Available: https:// www.iea.org/reports/international-shipping\#tracking-progress.

[4] Stopford M. Maritime economics. third ed. New York: Routledge - Taylor \& Francis Group - London and; 2009.

[5] UNCTAD. Review of maritime transport. 2020.

[6] IMO. UN body adopts climate change strategy for shipping. 2018. http://www. imo.org/en/MediaCentre/PressBriefings/. [Accessed 18 August 2019].

[7] Sharmina M, et al. Decarbonising the critical sectors of aviation, shipping, road freight and industry to limit warming to $1.5-2{ }^{\circ} \mathrm{C}$. Clim Pol 2020:1-20. https://doi.org/10.1080/14693062.2020.1831430. vol. 0, no. 0.

[8] Traut M, Larkin A, Anderson K, McGlade C, Sharmina M, Smith T. CO2 abatement goals for international shipping. Clim Pol 2018;18(8):1066-75. https://doi.org/10.1080/14693062.2018.1461059.

[9] Bullock S, Mason J, Broderick J, Larkin A. Shipping and the Paris climate agreement: a focus on committed emissions. BMC Energy 2020;2(1):5. https:// doi.org/10.1186/s42500-020-00015-2.

[10] Transport \& Environment. Statistical analysis of the energy efficiency performance (EEDI) of new ships. 2017 [Online]. Available: https://www. transportenvironment.org/sites/te/files/publications/Statistical analysis of the energy efficiency performance \%28EEDI\%29 of new ships.pdf.

[11] Dnv GL. Eexi - energy efficiency existing ship Index. 2021. https://www.dnv. $\mathrm{com} / \mathrm{maritime/insights/topics/eexi/index.html.}$

[12] Dnv GL. Decarbonization in shipping. 2021. https://www.dnv.com/maritime/ insights/topics/decarbonization-in-shipping/index.html.

[13] Balcombe P, et al. How to decarbonise international shipping: options for fuels, technologies and policies. Energy Convers Manag 2019;182(December 2018):72-88. https://doi.org/10.1016/j.enconman.2018.12.080.

[14] Dnv GL. Maritime forecast to 2050. 2020.

[15] Dnv GL. Comparison of alternative marine fuels. 2019 [Online]. Available: https://sea-lng.org/wp-content/uploads/2019/09/19-09-16_AlternativeMarine-Fuels-Study_final_report.pdf.

[16] Lloyd's Register and UMAS. Techno-economic assessment of zero-carbon fuels. Lloyds Regist.. March, 2020.

[17] Bouman EA, Lindstad E, Rialland AI, Strømman AH. State-of-the-art technologies, measures, and potential for reducing GHG emissions from shipping - a review. Transport Res Transport Environ 2017;52:408-21. https://doi.org/ 10.1016/j.trd.2017.03.022.

[18] Thepsithar P. Alternative fuels for international shipping. Singapore Marit. Inst. - Nanyang Technol. Univ. - Marit. Energy Sustain. Dev. Cent. Excell.; 2020.

[19] Esmeijer K, Den Elzen M, Van Soest H. Analysing international shipping and aviation emission projections of integrated assessment models. PBL Netherlands Environ. Assess. Agency; September, 2020 [Online]. Available: https://www.pbl.nl/sites/default/files/downloads/pbl-2020-analysing-international-shipping-and-aviation-emissions-projections_4076.pdf.

[20] Grubler A, et al. A low energy demand scenario for meeting the $1.5{ }^{\circ} \mathrm{C}$ target and sustainable development goals without negative emission technologies. Nat Energy 2018;3(6):515-27. https://doi.org/10.1038/s41560-018-0172-6.

[21] Rogelj J, Shindell D, Jiang K, Fifita S, Forster P. Mitigation pathways compatible with long-term goals. IPCC spec. Rep. Glob. Warm. $1.5^{\circ} \mathrm{C}$. 2018.

[22] Gambhir A, et al. Assessing the feasibility of global long-term mitigation scenarios. Energies 2017;10(1). https://doi.org/10.3390/en10010089.

[23] Huppmann D, et al. A new scenario resource for integrated $1.5{ }^{\circ} \mathrm{C}$ research. Nat Clim Change 2018. https://doi.org/10.1038/s41558-018-0317-4.

[24] Müller-Casseres E, et al. Production of alternative marine fuels in Brazil: an integrated assessment perspective. Energy 2020;219:119444. https://doi.org/ 10.1016/j.energy.2020.119444. 
[25] Stehfest E, van Vuuren D, Kram T, Bouwman L, Alkemade R, Bakkenes M, Biemans H, Bouwman A, den Elzen M, Janse J, Lucas P, van Minnen J, Müller C. Prins, Image 3.0. 2014.

[26] Notteboom T, Cariou P. Slow steaming in container liner shipping: is there any impact on fuel surcharge practices? Int J Logist Manag Jan. 2013;24(1):73-86. https://doi.org/10.1108/IJLM-05-2013-0055.

[27] Cariou P. Is slow steaming a sustainable means of reducing $\mathrm{CO} 2$ emissions from container shipping? Transport Res Transport Environ 2011;16(3):260-4. https://doi.org/10.1016/j.trd.2010.12.005.

[28] Clarksons Research. In it for the long-haul. And the short-haul Too. 2016. https://clarksonsresearch.wordpress.com/2016/08/12/in-it-for-the-longhaul-and-the-short-haul-too/. [Accessed 12 May 2021].

[29] UNCTAD. Review of maritime transport 1997. 1997.

[30] Vermeire M. Everything You need to Know about marine fuels. 2012 [Online]. Available: https://www.chevronmarineproducts.com/content/dam/chevronmarine/Brochures/Chevron_EverythingYouNeedToKnowAboutFuels_v3_1a_ DESKTOP.pdf.

[31] Maloni M, Paul JA, Gligor DM. Slow steaming impacts on ocean carriers and shippers. Marit Econ Logist 2013;15(2):151-71. https://doi.org/10.1057/ mel.2013.2.

[32] Ship \& Bunker. Idle boxship capacity reaches record high: alphaliner. News \& Features; 2020.

[33] ICCT. The energy efficiency design index (EEDI) for new ships. 2011 [Online]. Available: www.theicct.org.

[34] PBL. Welcome to IMAGE 3.0 documentation. 2020. https://models.pbl.nl/ image/index.php/Welcome_to_IMAGE_3.0_Documentation.

[35] Woltjer GB, et al. The agricultural world in equations: an overview of the main models at LEI. 2011.

[36] Armington PS. A theory of demand for products distinguished by place of production. IMF Staff Pap 1969;16(1):159-78 [Online]. Available: http:// www.palgrave-journals.com/imfsp/journal/v16/n1/full/imfsp19697a.html\% 5Cnhttp://www.palgrave-journals.com/imfsp/journal/v16/n1/pdf/ imfsp19697a.pdf.

[37] Van Ruijven BJ, Van Vuuren DP, Boskaljon W, Neelis ML, Saygin D, Patel MK. Long-term model-based projections of energy use and $\mathrm{CO} 2$ emissions from the global steel and cement industries. Resour Conserv Recycl 2016;112: 15-36. https://doi.org/10.1016/j.resconrec.2016.04.016.

[38] Bauer N, et al. Shared socio-economic pathways of the energy sector quantifying the narratives. Global Environ Change 2017;42:316-30. https:// doi.org/10.1016/j.gloenvcha.2016.07.006.

[39] Riahi K, et al. The Shared Socioeconomic Pathways and their energy, land use, and greenhouse gas emissions implications: an overview. Global Environ Change 2017;42:153-68. https://doi.org/10.1016/j.gloenvcha.2016.05.009.

[40] Kc S, Lutz W. The human core of the shared socioeconomic pathways: population scenarios by age, sex and level of education for all countries to 2100 . Global Environ Change 2017;42:181-92. https://doi.org/10.1016/ j.gloenvcha.2014.06.004.

[41] O'Neill BC, et al. The roads ahead: narratives for shared socioeconomic pathways describing world futures in the 21st century. Global Environ Change 2017;42:169-80. https://doi.org/10.1016/j.gloenvcha.2015.01.004.

[42] van Vuuren DP, et al. Energy, land-use and greenhouse gas emissions trajectories under a green growth paradigm. Global Environ Change 2017;42: 237-50. https://doi.org/10.1016/j.gloenvcha.2016.05.008.

[43] Fricko O, et al. The marker quantification of the Shared Socioeconomic Pathway 2: a middle-of-the-road scenario for the 21st century. Global Environ Change 2017;42:251-67. https://doi.org/10.1016/j.gloenvcha.2016.06.004.

[44] Fujimori S, et al. SSP3: AIM implementation of shared socioeconomic pathways. Global Environ Change 2017;42:268-83. https://oi.org/10.1016/ j.gloenvcha.2016.06.009.

[45] Calvin K, et al. The SSP4: a world of deepening inequality. Global Environ Change 2017;42:284-96. https://doi.org/10.1016/j.gloenvcha.2016.06.010.

[46] Kriegler E, et al. Fossil-fueled development (SSP5): an energy and resource intensive scenario for the 21st century. Global Environ Change Jan. 2017;42: 297-315. https://doi.org/10.1016/j.gloenvcha.2016.05.015.

[47] Doelman JC, et al. Exploring SSP land-use dynamics using the IMAGE model: regional and gridded scenarios of land-use change and land-based climate change mitigation. Global Environ Change 2018;48(November 2017):119-35. https://doi.org/10.1016/j.gloenvcha.2017.11.014.

[48] Stehfest E, et al. Key determinants of global land-use projections. Nat Commun 2019;10(1):1-10. https://doi.org/10.1038/s41467-019-09945-w.

[49] UNCTAD. Review of maritime transport 2019. 2019.

[50] Gazprom. Power of Siberia. 2020. https://www.gazprom.com/projects/powerof-siberia/.

[51] Gazprom. Nord stream. 2020. https://www.gazprom.com/projects/nordstream/.

[52] TC Energy. Keystone pipeline system. 2020 [Online]. Available: https://www. tcenergy.com/operations/oil-and-liquids/keystone-pipeline-system/.

[53] Petrobras. Gasoduto Brasil-Bolívia. 2020. https://petrobras.com.br/pt/nossasatividades/principais-operacoes/gasodutos/gasoduto-brasil-bolivia-trechosul.htm.

[54] Sea Distance. Sea distance. 2021. https://sea-distances.org/.

[55] Lindstad H, Eskeland GS. Low carbon maritime transport: how speed, size and slenderness amounts to substantial capital energy substitution. Transport Res Transport Environ 2015;41:244-56. https://doi.org/10.1016 j.trd.2015,10.006.

[56] IMO. Third IMO GHG study 2014 - Executive summary and final Report. International Maritime Organization; 2015.

[57] Vale. Valemax. 2014 [Online]. Available: http://www.vale.com/PT/initiatives/ innovation/valemax/Documents/valemax/pdf/VAL VALEMAX single.pdf.

[58] Kristensen $\mathrm{HOH}$. Determination of Regression Formulas for main dimensions of Tankers and bulk carriers based on IHS Fairplay data. no. 2010. 2012. p. 35.

[59] Man. Propulsion trends in bulk carriers. MAN Energy Solut.; 2015 [Online] Available: http://ezproxy.library.ubc.ca/login?. https://search.proquest.com/ docview/1751202257? accountid=14656. http://gw2jh3xr2c.search. serialssolutions.com/directLink? \&atitle=PROPULSION+TRENDS+ $\mathrm{IN}+$ BULK + CARRIERS\&author $=$ Anonymous \&issn $=\&$ title $=$ The + Marine + Profession.

[60] Mitsui OSK Lines. Resource transport. 2020. /iroiro_fune_e/01resources.html\#: :text=The "Capesize" is the largest,the Pacific and Atlantic oceans.

[61] Vale. Conheça melhor a segunda geração dos navios Valemaxes, os mais eficientes do mundo. 2018.

[62] Transpetro. Transpetro fleet. 2019. http://transpetro.com.br/en_us/ transpetro-institucional/business-areas/maritime-transportation/transpetrofleet/suezmax.htm.

[63] Bulk Carrier Guide. Various bulk carriers sizes and employment guide. 2010.

[64] Vessel Finder. Vessel Finder. 2020. https://www.vesselfinder.com/.

[65] Gilbert P, Walsh C, Traut M, Kesieme U, Pazouki K, Murphy A. Assessment of full life-cycle air emissions of alternative shipping fuels. J Clean Prod 2018;172(2018):855-66. https://doi.org/10.1016/j.jclepro.2017.10.165.

[66] Kim K, Roh G, Kim W, Chun K. A preliminary study on an alternative ship propulsion system fueled by ammonia: environmental and economic assessments. J Mar Sci Eng 2020;8(3). https://doi.org/10.3390/jmse8030183.

[67] Statista. Global biofuel production by select country 2019. 2020. https://www statista.com/statistics/274168/biofuel-production-in-leading-countries-inoil-equivalent/\#: :text=Global biofuel production has gradually [fuel sources or as additives].

[68] Kesieme U, Pazouki K, Murphy A, Chrysanthou A. Biofuel as an alternative shipping fuel: technological, environmental and economic assessment. Sustain Energy Fuels 2019;3(4):899-909. https://doi.org/10.1039/C8SE00466H.

[69] IEA Bioenergy. Biofuels for the marine shipping sector. October, 2017.

[70] Tagomori IS, Rochedo PRR, Szklo A. Techno-economic and georeferenced analysis of forestry residues-based Fischer-Tropsch diesel with carbon capture in Brazil. Biomass Bioenergy Apr. 2019;123:134-48. https://doi.org/10.1016/ j.biombioe.2019.02.018. 